DOI: https//doi.org/10.13037/ci.vol22n49.7143

\title{
O processo de midiatização e a natureza midiática da religião
}

The mediatization process and the mediatic nature of religion

\author{
Viviane Borelli ${ }^{a}$ \\ ORCID: https://orcid.org/0000-0003-0643-2173 \\ Herivelton Regiani ${ }^{b}$ \\ ORCID: https://orcid.org/0000-0002-3221-7736
}

Recebido em: 15/07/2020. Aprovado em: 03/05/2021.

Resumo

A partir de proposições acerca da natureza midiática da experiência humana, buscamos ampliar a reflexão para poder se falar em uma natureza midiática da religião. Compreende-se o processo de midiatização da religião em escala temporal mais abrangente, não devendo ser tratado como um fenômeno circunscrito à atualidade. Refletimos sobre o processo de secularização e as mudanças complexas na interface entre religião e mídia. Aprofundamos bases teóricas para a compreensão do especificamente comunicacional em fenômenos religiosos atuais, que se desenvolvem e são reconfigurados segundo lógicas midiáticas.

Palavras-chave: Midiatização. Religião. Semiótica discursiva.

\begin{abstract}
Based on propositions about the media nature of human experience, we expand the reflection in order to speak about a mediatic nature of religion. The process of mediatizing religion is undertood on a more comprehensive timescale and should not be treated as a phenomenon confined to current societies. We reflected on the process of secularization and the complex changes in the interface between religion and the media. We deepened theoretical bases for the understanding of the specifically communicational in current religious phenomena, which are developed and reconfigured according to media logics.
\end{abstract}

Keywords: Mediatization. Religion. Discursive semiotics.

\section{Introdução}

A presente abordagem toma como ponto de partida proposições do livro O paradigma Comunicacional - história e teorias (RODRIGUES, 2011) e do artigo A Natureza Midiática da Experiência (RODRIGUES; BRAGA, 2014) para compreendermos o conceito de

\footnotetext{
${ }^{a}$ Universidade Federal de Santa Maria (UFSM), Rio Grande do Sul, Brasil. E-mail: viviborelli10@gmail.com

${ }^{\mathrm{b}}$ Universidade Federal de Santa Maria (UFSM), Rio Grande do Sul, Brasil. E-mail: heriveltonreg@gmail.com
} 
midiatização em uma processualidade histórica mais abrangente que a habitual. Nesse contexto, o objetivo do artigo é refletir sobre em que medida podemos pensar numa natureza midiática da religião ${ }^{1}$. Trata-se, portanto, de reflexão majoritariamente teórica, que aciona exemplos para ampliar a discussão sobre o processo de midiatização da sociedade e das práticas religiosas. Concordamos que a midiatização é uma das manifestações constituintes do modo como o homo sapiens experimenta a realidade e dá sentido às suas práticas (VERÓN, 2012, 2013 e 2014).

No centro da discussão efetuada por Adriano Duarte Rodrigues e Adriana Braga (2014) A Natureza Midiática da Experiência (RODRIGUES; BRAGA, 2014) está a asserção de que a experiência humana de apreensão da realidade sempre se deu através de dispositivos midiáticos, ou seja, de que essa característica não é algo que ocorre somente em nosso tempo, reconhecidamente marcado pela emergência constante de novos dispositivos tecnológicos.

Tal afirmação dos autores sobre a natureza midiática da ação humana no mundo nos levou a refletir também sobre a possibilidade de se falar em uma natureza midiática da religião. Afinal, a religião é uma das manifestações culturais em que se mostra de forma mais evidente a capacidade humana de criação de símbolos, formas de interação e dispositivos culturais e técnicos para construção e disseminação de sentidos.

Essa processualidade comunicacional e midiática ${ }^{2}$, característica das religiões, se mostra também na atualidade, com a profusão de produções em diferentes dispositivos, apropriandose de linguagens e tecnologias que vão desde os "tradicionais", como rádio e a televisão, até o ambiente digital da internet e das plataformas de redes sociais digitais. Não somente igrejas e instituições religiosas, mas também coletivos e atores sociais individuais elaboram, adaptam e difundem variados discursos, em um processo contínuo de arranjos linguísticos e reconfiguração de estratégias para se manterem conectados a seus seguidores e possibilitarem a conquista de novos participantes e fiéis ${ }^{3}$.

\footnotetext{
${ }^{1}$ Uma primeira versão do artigo foi apresentada no GP Comunicação e Religião do XVIII Encontro dos Grupos de Pesquisas em Comunicação, evento componente do $41^{\circ}$ Congresso Brasileiro de Ciências da Comunicação, que Intercom - Sociedade Brasileira de Estudos Interdisciplinares da Comunicação, que aconteceu em Joinville - SC, de 2 a 8/09/2018. Após discussão com os colegas de GP, sugestões foram incorporadas para esta versão.

${ }^{2}$ Compreende-se, nessa perspectiva, que a atividade comunicacional humana, até mesmo nas interações face a face, tem como especificidade a construção de dispositivos artificiais, desde a linguagem até os dispositivos de mediação que caracterizamos como mídias. A atividade comunicacional humana, dessa forma, é também atividade midiática, como veremos na sequência. Para aprofundar essa visão, ver Rodrigues (2011).

3 Essas transformações são problematizadas por Fausto Neto (2002), Borelli (2010), White (1997), entre outros tantos pesquisadores que estudaram e pesquisam aspectos relativos às complexas interfaces entre mídia e religião. Há que se fazer também menção ao GP da Intercom "Comunicação e Religião", que tem reunido alunos de pósgraduação, professores e profissionais, sob coordenação de Magali Cunha. 
Inicialmente, as religiões ocuparam espaços nas grades de programação de rádio e televisão, chegando a adquirir emissoras e grupos de comunicação ${ }^{4}$. Posteriormente, de maneira mais difusa e significativa, passaram a produzir sites, canais, páginas e perfis com grande visibilidade em plataformas digitais (VAN DIJCK; POELL; DE WAAL, 2018) como o Youtube, Facebook e Twitter, além de blogs e outros formatos. Trazem para a esfera pública temas de seu interesse, bem como repercutem e reelaboram temáticas oriundas de outros campos sociais.

Como defende White (1997, p.26), durante algum tempo a religião imaginou ser possível "recuperar seu senso de sagrado, apenas deixando o confinamento das igrejas e dogmas, e mudando-se para o mundo secular", no qual os distintos ambientes midiáticos tornaram-se um lugar estratégico de "criação dos símbolos de religião" (WHITE, 1997, p.26). Dessa forma, quando se fala em midiatização da religião, problematiza-se distintas transformações nos modos de funcionamento do próprio campo religioso, ou seja, é um fenômeno que não se resume à transposição de conteúdo ou a estar na mídia, mas que repercute sobre o modo de se vivenciar as religiosidades ${ }^{5}$.

Assim, a interface entre mídia e religião tem se mostrado continuamente rica e instigante como objeto de estudo, haja vista a profusão de pesquisas na Sociologia, Antropologia e nas Ciências da Religião. Entretanto, objetivamos uma abordagem que atente para o que problematiza Signates (2013) sobre a necessidade de refletir sobre o que há de especificamente comunicacional nos estudos realizados no campo da Comunicação no Brasil. Acompanhando esse autor, consideramos que os aspectos comunicacionais devem ocupar uma posição central nos estudos de nossa área voltados para a interface com as religiões, mesmo que a diversidade faça "parte do modo de ser do conhecimento" (SIGNATES, 2013, p.20).

Baseamo-nos também no que destaca Braga (2011) acerca da constituição do campo da Comunicação. Para ele, a afirmação de que a Comunicação é um campo interdisciplinar é óbvia,

\footnotetext{
${ }^{4}$ Sobre esse momento histórico de utilização das mídias por parte de distintas denominações para evangelização, pode-se ser consultado ASSMANN, Hugo. A Igreja Eletrônica e seu impacto na América Latina. Petrópolis: Vozes, 1986. Aspectos históricos das relações entre mídia e religião foram abordadas por GOMES, Pedro Gilberto. Processos Midiáticos e Construção de Novas Religiosidades: Dimensões Históricas. Cadernos IHU 2 (8), 6-10. 2004. In: http://www.ihu.unisinos.br/images/stories/cadernos/ihu/008cadernosihu.pdf

${ }^{5}$ Falar em midiatização da religião, nesse sentido (assim como em midiatização da política, da economia e outras aplicações do termo), não significa apenas apontar para o uso frequente das mídias ou para o impacto das mídias sobre um campo específico, mas apontar para como a atividade de construção de sentidos está atravessada por lógicas midiáticas. Ou seja, não se trata de uma visão institucional da midiatização da religião (focada nos meios), mas sim de processos complexos de trocas simbólicas entre os atores sociais que fazem parte e constroem esse fenômeno. Pode-se aprofundar o conceito em Verón (1997, 2012, 2013 e 2014), que, desde os anos 80 até suas últimas obras, problematizou que o termo "midiatização" está atrelado ao processo de semiose social.
} 
visto que todo conhecimento é atravessado por saberes de vários campos, mas também é uma premissa que se mostra vazia, pois pressupõe haver um conjunto específico de disciplinas sem uma preocupação central.

Afirma o autor que o interdisciplinarismo foi usado durante décadas para explicar os estudos em Comunicação e justificar sua dispersão. Portanto, avalia que o desafio a ser enfrentado pelos pesquisadores é mostrar as interfaces entre a Comunicação e outras áreas do conhecimento constituindo "um verdadeiro e efetivo trabalho de interdisciplinaridade - desde que leve a sério a busca dos enfoques comunicacionais" (BRAGA, 2011, p.64).

Nessa conjuntura, tendo a Comunicação como lugar de partida e como nosso campo de saber, revisitamos conceitos importantes para a compreensão da religião enquanto fenômeno comunicacional. Com isso, criam-se as bases para um entendimento mais aprofundado das raízes históricas de processualidades, tanto religiosas quanto midiáticas, que também se evidenciam na contemporaneidade ${ }^{6}$.

Como um dos principais referenciais para compreensão do cenário comunicacional contemporâneo, concordamos com Braga (2006) e Verón (2012, 2014), que compreendem que a sociedade está em vias de midiatização. Trata-se de um processo em curso, e não de uma realidade consolidada, ou dominada por uma só forma estruturante que explicaria a totalidade de seu funcionamento. Seguindo as proposições de Braga (2006), compreendemos a midiatização como processo interacional de referência, que deixa marcas também no campo religioso.

Lembramos, com Verón (2012, 2013 e 2014), que a midiatização não é apenas um fenômeno atual. Mesmo que, recentemente, haja uma aceleração desse processo social, por conta da emergência de novos dispositivos midiáticos, "a midiatização começou em torno de 200 mil anos, quando apareceu, assim mais ou menos, a temporalidade das últimas discussões sobre a origem da espécie” (VERÓN, 2012, p.18).

Assim, concordamos com o semiólogo argentino, pois entendemos que é preciso situar a relação entre comunicação e midiatização e, portanto, entre midiatização e religião, em uma perspectiva histórica mais alargada, tornando-se pertinente destacar a natureza midiática da

\footnotetext{
${ }^{6} \mathrm{O}$ autor desenvolve, atualmente, pesquisa doutoral intitulada "Riso sagrado: a comicidade como estratégia discursiva na midiatização da religião" que investiga o lugar que o humor ocupa na constituição de estratégias midiáticas e práticas discursivas do cristianismo no contexto da midiatização. O trabalho, em desenvolvimento no Programa de Pós-Graduação em Comunicação da Universidade Federal de Santa Maria tem orientação da professora Viviane Borelli, que dedicou parte de sua produção acadêmica para refletir sobre as interfaces entre mídia e religião. 
religião. Afinal, o fenômeno religioso é intrínseco à experiência humana e, ao longo da história, evidencia modos comunicacionais de se constituir. 


\section{A natureza midiática da experiência e a religião}

Diante da invenção, em ritmo acelerado, de novos dispositivos midiáticos e de sua rápida assimilação na sociedade contemporânea, há o risco de nos apressarmos em afirmar que estamos diante de modos completamente diferentes de ação humana e vida em sociedade. Passamos a identificar como totalmente novas algumas características humanas e sociais que, na verdade, existem desde o início da história, mas que hoje assumem roupagens e intensidades diferenciadas.

Essa é a convicção de Rodrigues e Braga (2014), que destacam a linguagem como o primeiro dispositivo midiático de que se valeu o ser humano, seguida de vários outros dispositivos e objetos técnicos que tornam, desde o princípio, a nossa experiência de mundo dependente de atividades midiáticas. Para esses autores, a experiência técnica está relacionada com o próprio processo de tornar-se humano (hominização). Ao contrário dos demais animais, que se adaptam e evoluem do ponto de vista biológico para fazer frente aos desafios do ambiente, pode-se dizer que o ser humano "involui" biologicamente, pois reage ao mundo que o cerca predominantemente por meio do desenvolvimento de objetos técnicos.

Esses objetos, acoplados ao corpo ou postos a funcionar de modo independente dele, são mediadores de sua apreensão da realidade e de sua interferência no mundo. Alguns objetos técnicos passam a se constituir como dispositivos, à medida em que são incorporados ao organismo dos seres humanos, atuando como formas de interagir com o mundo e de provocar reações de outros organismos (RODRIGUES; BRAGA, 2014).

Nesse ponto é preciso lembrar que Rodrigues (2011, p.25) compreende o conceito de comunicação como "troca de experiência entre os seres humanos", afastando-se de abordagens que o reduzem à instrumentalização. Para o autor, o objetivo dos dispositivos técnicos é realizar, de forma artificial, "as competências que os seres humanos realizam espontaneamente quando interagem entre si e com o mundo" (RODRIGUES, 2011, p.25). Assim, ao longo da história, o homem criou distintos dispositivos técnicos para dar conta de suas necessidades de sobrevivência e de comunicação.

O primeiro e fundamental dispositivo de mediação, segundo Rodrigues (2011, p.69), é o corpo. Nele "se desencadeiam os processos sensoriais que presentificam, de algum modo, o mundo, dispondo-o de acordo com a maneira como o corpo está sensorialmente equipado e colocado à nossa disposição". O corpo é, portanto, nosso dispositivo natural, pois já chegamos 
ao mundo com essa constituição e natureza, que permitem relações com o exterior de distintas formas e diferentes modos de apreensão do outro. ${ }^{7}$

Entretanto, conceitua o autor, os modos de funcionamento do corpo na relação com os outros não são dados, pois, para poder "desencadear respostas aos estímulos do mundo envolvente, necessitam da aprendizagem de modalidades de mediatização inventadas, do enxerto, da interiorização ou da incorporação de dispositivos mediáticos artificiais" (RODRIGUES, 2011, p.69). Ao longo da história, o ser humano avaliou ser necessário criar dispositivos artificiais, que o autor conceitua como sendo dispositivos culturais, que possibilitam complementar sua natureza para melhor acionar o mundo.

Seguindo essa perspectiva teórica, é mais coerente situar o conceito de midiatização não apenas em uma contemporaneidade atravessada por múltiplos dispositivos tecnológicos, mas em um tempo histórico muito maior. É o que fez Eliseo Verón em suas reflexões sobre o conceito de midiatização desde os anos 80 em distintas obras ${ }^{8}$. Para Verón $(2012,2014)$, a midiatização é compreendida como uma exteriorização dos processos mentais em dispositivos visuais e técnicos que vão da invenção de instrumentos de pedra, passando pelas representações visuais rupestres, pela escrita e pelas tecnologias de comunicação contemporâneas. Trata-se da “exteriorização de processos cognitivos, que aparentemente é uma disposição da espécie (...). Então, a midiatização vem de muito longe, vem com a espécie e tem características particulares nos últimos tempos" (VERÓN, 2012, p.18).

Portanto, o processo de midiatização não é algo verificável apenas nas sociedades chamadas de modernas, mas um processo resultante da própria capacidade humana de semiose, ou seja, a natureza humana pressupõe que somos seres produtores de sentidos.

Neste contexto, a midiatização é apenas o nome para a longa sequência histórica de fenômenos midiáticos sendo institucionalizados em sociedades humanas e suas múltiplas consequências. A vantagem conceitual da perspectiva de longo prazo é nos relembrar que o que está acontecendo nas sociedades da modernidade tardia começou, de fato, há muito tempo (VERÓN, 2014, p. 15 e 16).

Além disso, o autor ressalta que a midiatização não se desenvolve de maneira linear, mas segundo padrões de aceleração que se moldam em contextos específicos e conforme o

\footnotetext{
${ }^{7}$ Note-se, aqui e na sequência, como essa perspectiva compreende o comunicacional e midiático de maneira mais abrangente, em uma abordagem que atenta para os dispositivos de mediação como elementos indissociáveis da experiência humana em sua interação com o mundo. Para aprofundar, ver Rodrigues (2011) e Verón (2013).

8 Sobre as relações, aspectos convergentes e divergentes e os conceitos de mediação e de midiatização, FAUSTO NETO (2018) traça um paralelo minucioso entre as perspectivas de Martín-Barbero e de Verón no contexto de produção acadêmica da América Latina.
} 
surgimento de novos meios de comunicação. Assim, midiatização é um processo que assumiu diferentes formas em períodos anteriores, mas aprofundou-se com a aceleração do tempo histórico que é uma característica do momento atual.

Em um movimento evolutivo, cada novo dispositivo técnico comunicacional gera efeitos que afetam as sociedades em diferentes intensidades ${ }^{9}$. Verón (2014) cita como exemplo três períodos especiais em que considera ter havido uma aceleração do tempo histórico, reconhecendo que outros poderiam ser arrolados: as ferramentas de pedra do Alto Paleolítico; a invenção da prensa de tipos móveis no século XV; e, nos últimos anos, a internet.

A exteriorização dos processos cognitivos é compreendida como uma disposição natural da espécie, que pressupõe sempre um suporte material: a pedra, a escrita, a imprensa e mais recentemente a digitalização. Nesse sentido, o desafio a ser encarado pelos pesquisadores e historiadores dos meios é buscar o dispositivo técnico da comunicação para compreender as transformações. "Precisamos de uma teoria dos "mundos semióticos", que é essa história vista pelo ponto de vista da evolução da comunicação e dos dispositivos técnicos" (VERÓN, 2012, p.22).

Nessa perspectiva, não se trata a midiatização como fenômeno inédito na história da humanidade, mas destaca-se que vivemos em um tempo no qual a dinâmica da midiatização se mostra mais acelerada. A comunicação midiática é uma "configuração de meios de comunicação resultantes da articulação entre dispositivos tecnológicos e condições específicas de produção e recepção, configuração que estrutura o mercado discursivo das sociedades industriais"10 (VERÓN, 1997, p.14, tradução nossa).

Nesse sentido, para o autor, os dispositivos midiáticos não possuem apenas características tecnológicas, mas também discursivas e sociais, visto que remetem a situações singulares de produção, recepção e circulação discursiva. Nas sociedades industriais, as condições sociais de acesso e uso das mensagens das quais os meios de comunicação são suportes estão também ligadas a uma economia que torna possível "definir os meios de comunicação como um mercado e caracterizar o conjunto como oferta discursiva" ${ }^{11}$ (VERÓN, 1997, p. 14, grifo do autor, tradução nossa).

\footnotetext{
${ }^{9}$ Scolari (2018, p. 14) também problematiza essas transformações técnicas e propõe um modelo no qual dialoguem aspectos históricos, semióticos, biológicos, tecnológicos, culturais, entre outros, a partir de um olhar interdisciplinar que vincula o que intitula esferas tecnocultural e bionatural.

10 La comunicación mediática es esa configuración de medios de comunicación resultantes de la articulación entre dispositivos tecnológicos y condiciones específicas de producción e recepción, configuración que estructura el mercado discursivo de las sociedades industriales.

$11[\ldots]$ 
O autor avalia que a evolução e a emergência dos dispositivos tecnológicos geram uma aceleração também das práticas sociodiscursivas como resultado da própria mudança da demanda. Portanto, mesmo que o processo de midiatização não seja apenas um fenômeno recente, "a partir de certo ponto, a comunicação midiática gera um processo de midiatização das sociedades industriais"12 (VERÓN, 1997, p. 14, tradução nossa).

É preciso referir que, em uma de suas últimas produções, Verón (2013) coloca a questão da midiatização a partir da problemática da circulação discursiva - que durante muito tempo era vista como um lugar de passagem entre produção e recepção. Para ele, o desenvolvimento das sociedades e dos dispositivos tecnológicos e discursivos implica também em mudanças no mercado discursivo. Assim, a complexidade dos fenômenos de circulação passa a desafiar os pesquisadores a olharem com atenção para esse lugar e não mais apenas para duas instâncias estanques - a produção e a recepção.

\section{A midiatização da religião}

Refletindo sobre a experiência humana do sagrado, encontramos reforço para a compreensão do processo de midiatização da religião nessa larga escala temporal, especialmente pelo fato de que esta manifesta, desde o início, a criação de artefatos e dispositivos de linguagem que atuam à semelhança de mídias ou medium entre o mundo material e o espiritual, entre os homens e os seres ou realidades assumidas como alvo de fascínio e temor (OTTO, 1985).

A própria palavra religião, em sua origem latina religare, aponta para uma busca de conexão, de religação ao sagrado. Essa busca por conexão é construída por mitos - narrativas com o objetivo de firmar verdades fundamentais em bases sobrenaturais - e ritos - atividades que reiteram e reforçam os mitos. Esses mitos e ritos são constituídos e celebrados através de dispositivos de linguagem e artefatos concretos que atuam como ferramentas técnicas para essa finalidade.

Quando, em sociedades ainda anteriores à escrita, os homens se reuniam para a prática ritual, inscreviam nos seus corpos ou nas cavernas seus desejos, passagens, conquistas ou descobertas, estavam certamente exteriorizando processos mentais no que consideravam sua

\footnotetext{
"definir el sector de los medios de comunicación como um mercado y caracterizar el conjunto como oferta discursiva".

12 [...] "a partir de certo ponto, la comunicación mediática genera um processo de mediatización de las sociedades industriales".
} 
comunicação com as entidades sagradas. Os cânticos, as imagens, os artefatos de caráter mágico, as marcas e inscrições em suas ferramentas de caça ou combate e outras tantas produções atuavam como dispositivos para a apreensão e conservação do poder sagrado.

Desse modo, muitas das criações humanas que se tornaram importantes enquanto dispositivos de apreensão da realidade, de ação sobre a mesma e de enunciação dos sentidos a partir dela construídos eram, em sua história inicial, revestidos de uma intensa e quase ubíqua sacralidade. Como afirmam Rodrigues e Braga (2014, p.194), "é nos seus artefatos que os seres humanos parecem pretender perpetuar-se a si próprios e ao seu mundo para além da efemeridade da sua existência mortal".

É o que ocorria, por exemplo, com as imagens. De acordo com Flusser (1993), desde a pré-história, as imagens foram fundamentais no exercício da representação e no desenvolvimento do homem e da cultura. Inicialmente, eram revestidas de um caráter marcadamente mágico, como objetos de culto ou eminentemente ligados ao sagrado. Posteriormente, com o estabelecimento de uma cultura mais voltada à escrita como forma de compreensão do mundo, é que foi se desenvolvendo maior independência entre a arte das imagens e a representação do mágico e do sagrado.

Essa desvinculação ou independência entre a esfera do sagrado e as demais dimensões da experiência humana, que começou a se desenhar em alguns processos sociais que remontam à antiguidade, acabou por se intensificar nas sociedades industriais. Isso, porém, não implicou em perda do caráter midiático da religião. Ao contrário, implicou em uma reconfiguração dos modos pelos quais ela continua a se midiatizar.

As questões religiosas ainda permanecem vivas e, por vezes, ganham visibilidade como componentes importantes do tecido social, mas a autoridade e a legitimidade conferidas às religiões na sociedade como um todo já não são as mesmas.

Nesse contexto histórico, o processo de midiatização da religião continua a se desenvolver em meio a tentativas constantes de religiões de encontrar novas estratégias para permanecerem conectadas a seus seguidores. Da mesma forma, ocorrem esforços das instituições religiosas para obter o reconhecimento de seus problemas e demandas por toda a sociedade, na relação complexa com outros campos sociais ${ }^{13}$.

Se olharmos, por exemplo, para as três grandes religiões que influenciaram o Ocidente, podemos dizer que no Judaísmo, no Cristianismo e no Islamismo a palavra, escrita e proclamada,

\footnotetext{
13 Há várias pesquisas que problematizam essas relações, especialmente aquelas entre os campos midiático e religioso que, neste espaço, não poderão ser aprofundadas. 
sempre ocupou uma posição central. São religiões cujos ensinamentos se materializam em livros sagrados e subsistem durante muito tempo em uma cultura marcadamente literária. Essas tradições religiosas, apesar das diferenças que guardam entre si, reivindicam uma palavra divina revelada como fonte. Como Armstrong (1995) afirma, o conceito da palavra divina é crucial para judeus, cristãos e muçulmanos, e essa ênfase na Palavra de Deus moldou a história da nossa cultura ocidental.

No cristianismo, de modo particular, o próprio Jesus Cristo, tido como salvador e centro de sua fé, é descrito como a Palavra (em grego, logos) encarnada ${ }^{14}$. Acredita-se que todas as coisas foram criadas por meio dessa palavra divina (uma menção à criação do mundo pela voz de Deus em Gênesis). Finalmente, essa palavra que se encarnou para salvar os seres humanos, restabelecendo a relação comunicativa com Deus.

Na Bíblia, Deus é descrito desse modo, como alguém que fala ao ser humano e comunica sua vontade para todas as esferas da vida. Alguém com quem também é possível se comunicar, pela oração realizada em nome do messias mediador. A vida individual e social dos cristãos, assim como as ações das instituições religiosas a que eles se vinculam, é pautada pela adequação à palavra divina revelada ou a ela se refere para sua legitimação.

Com a secularização que marca a modernidade (RODRIGUES, 1999) - embora esta tenha ritmos e situações diferentes conforme os variados contextos sociais - ocorre uma importante mudança nesse relacionamento tradicional do ser humano com a palavra. Se, antes, ela era divinamente naturalizada, legitimada e estabelecida, a partir de então passou a ser problematizada como fenômeno estritamente humano. Isso ocorre, como observa Vera França, de modo concomitante com o surgimento da comunicação como um problema de estudo. "A modernidade transformou a comunicação em problema; levantou questões em torno de uma prática até então natural, naturalizada - prática essa que desde então se impôs aos homens como algo a ser melhor conhecido" (FRANÇA, 2001, p.46).

Rodrigues (1999) descreve esse movimento histórico como uma dessacralização da experiência do mundo, um processo de autonomização das dimensões da experiência que ele denomina "a época da autonomização do campo dos media" (RODRIGUES, 1999, p. 2). A autonomização dos campos sociais ocorre de tal forma que a mídia se torne não apenas um campo mediador entre os outros, dando-lhes voz e visibilidade diante da sociedade como um

14 Do evangelho de João, capítulo primeiro, em que se afirma o messias como a palavra ou razão preexistente ao mundo, que estava com Deus, era Deus e por meio da qual todas as coisas foram criadas. 
todo, mas também como um mobilizador em torno de questões às quais vários campos devem, à sua maneira e em seu domínio específico, responder.

\section{Processualidades em construção}

Para Hjavard (2008), que dedicou-se à compreensão do fenômeno da midiatização da religião, embora a grande presença de temas religiosos na mídia atual possa parecer uma negação da secularização, ainda existe uma forte tendência para essa desvinculação do sagrado das demais esferas da sociedade. Dessa forma, a midiatização da religião pode ser considerada parte de uma secularização gradual, na qual a mídia vem se ocupando das funções sociais que foram realizadas por instituições religiosas. Estudar como a religião se entrelaça com a mídia pode mostrar como a secularização e a "ressacralização" podem ocorrer simultaneamente em diferentes interfaces entre religião e mídia. Embora não seja essa a perspectiva que adotamos em nosso estudo, pois está centrada na institucionalidade dos meios de comunicação, é um importante apontamento na direção de como a religião continua se midiatizando. Compreendemos que essa processualidade ocorre em contextos diferenciados e a partir de distintas práticas, não sendo especificamente uma questão institucional.

Hoje, o indivíduo encontra-se imerso em ambientes de múltiplos discursos, que competem pelo poder sobre sua consciência e modo de vida. Hoover (2006) argumenta que, na busca espiritual realizada por indivíduos, a legitimidade das instituições religiosas formais tem sido muitas vezes questionada, com o poder da legitimação cada vez mais nas mãos da pessoa que busca inspiração espiritual. Em sua busca pessoal, os sujeitos adotam uma ampla gama de fontes e contextos - além dos tradicionais - e a mídia se torna central para a compreensão das tendências e mudanças.

O autor ainda salienta que, no século XXI, a conexão entre a religião e a mídia se torna cada vez mais evidente no contexto global: muitas religiões distantes se tornam conhecidas pelos meios de comunicação; a questão do terrorismo impõe reflexões sobre as crenças religiosas e seu uso político; os escândalos da Igreja Católica ganham espaço nos grandes veículos de comunicação; confrontos públicos entre religiosos tradicionais e grupos que buscam mudanças, como as mulheres e os homossexuais; As questões religiosas continuam a ser importantes nas campanhas políticas dos EUA; o surgimento de questões religiosas também afeta a vida social europeia, com a questão da imigração. De acordo com o autor, tudo isso 
mostra que estamos em um mundo onde "a mídia e a religião se misturam e colidem na experiência cultural das audiências midiáticas" (HOOVER, 2006, p.13, tradução nossa ${ }^{15}$ ).

Nesse contexto, o paradigma teórico da midiatização tem muito a contribuir para a compreensão do novo lugar que a religiosidade ocupa na sociedade contemporânea e para o entendimento das formas que essa religiosidade assume. A partir dessa perspectiva, podem ser melhor compreendidos os processos pelos quais a religião se midiatiza ao buscar legitimidade e visibilidade em um contexto social no qual ela não mais ocupa uma posição central.

Para elucidar esse aspecto, cunhamos a seguinte metáfora: Imagine que a sociedade pudesse ser concebida, em sua estrutura, como uma cômoda, composta de várias gavetas (família, educação, justiça, estado, saúde etc.). Nas sociedades tradicionais, o que definia o formato, encaixes e contornos para cada uma das gavetas era a religião. Todas as demais esferas da sociedade, para obterem legitimidade, deveriam se encaixar seguindo ditames religiosos. $\mathrm{Na}$ atualidade, ocorre um imenso deslocamento. A religião, antes imbricada na estrutura da cômoda, torna-se apenas uma de suas gavetas, devendo se adequar a determinações vindas de outra fonte. No desenho, encaixes e moldes da cômoda social hoje atuam, de forma preponderante, as lógicas midiáticas.

Em outras palavras, na visada especificamente comunicacional que é possibilitada nas abordagens que tomam como referência o conceito de midiatização ${ }^{16}$, a busca é por entender as transformações e adequações pelas quais as religiões adotam como referência, em seus processos de interação, as lógicas e os modos de dar significado e de fazer que são próprios do campo midiático. Ou ainda, investigar em que medida se modificam, a partir das tentativas de inserção das religiões no espaço das mídias, os modos de produção, circulação e recepção dos discursos que lhe são próprios.

Como destacamos anteriormente, a religião subsistiu, sobretudo no ocidente, como parte de uma cultura literária. Hoje, em um contexto atravessado por outros dispositivos tecnológicos, os atores do campo religioso procuram adaptar sua linguagem e produzir conteúdo sagrado em formatos para o rádio, a televisão, e mais recentemente, a internet.

Tomemos como exemplo a proeminência de padres ou pastores como produtores de vídeos e outras formas de interação. Já havia uma grande variedade de produções via Youtube, Facebook, Instagram e outras plataformas digitais, destinadas a coletivos de seguidores que

\footnotetext{
15 "media and religion intermingle and collide in the cultural experience of media audiences".

${ }^{16}$ Martino (2018) oferece um interessante panorama a respeito da gênese e aplicações do conceito, bem como da diversidade de abordagens em contextos distintos.
} 
ultrapassavam as fronteiras do templo ou da denominação religiosa. Atores sociais como o padre católico Fábio de Melo (Figura 1) ou o pastor evangélico Cláudio Duarte (Figura 2), lançando mão, inclusive, do humor como estratégia de contato, adquiriram grande visibilidade e passaram a ser notados e acionados para além dos canais e produções religiosas.

Porém, no contexto da pandemia covid-19, que em 2020 impôs isolamento físico e interrupção de atividades presenciais, que afetou as igrejas e grupos religiosos, uma quantidade bem maior de atores do campo religioso lançou-se à internet e às plataformas digitais como ambiências para veiculação de suas mensagens e interação com seus públicos. Esse fenômeno tem suscitado pesquisas e verificações acerca das mudanças na produção de sentidos das religiões em midiatização, produção essa que já se efetua em uma dinâmica de circulação, com constantes e quase que imediatas reconfigurações conforme as reações, interações e compartilhamentos.

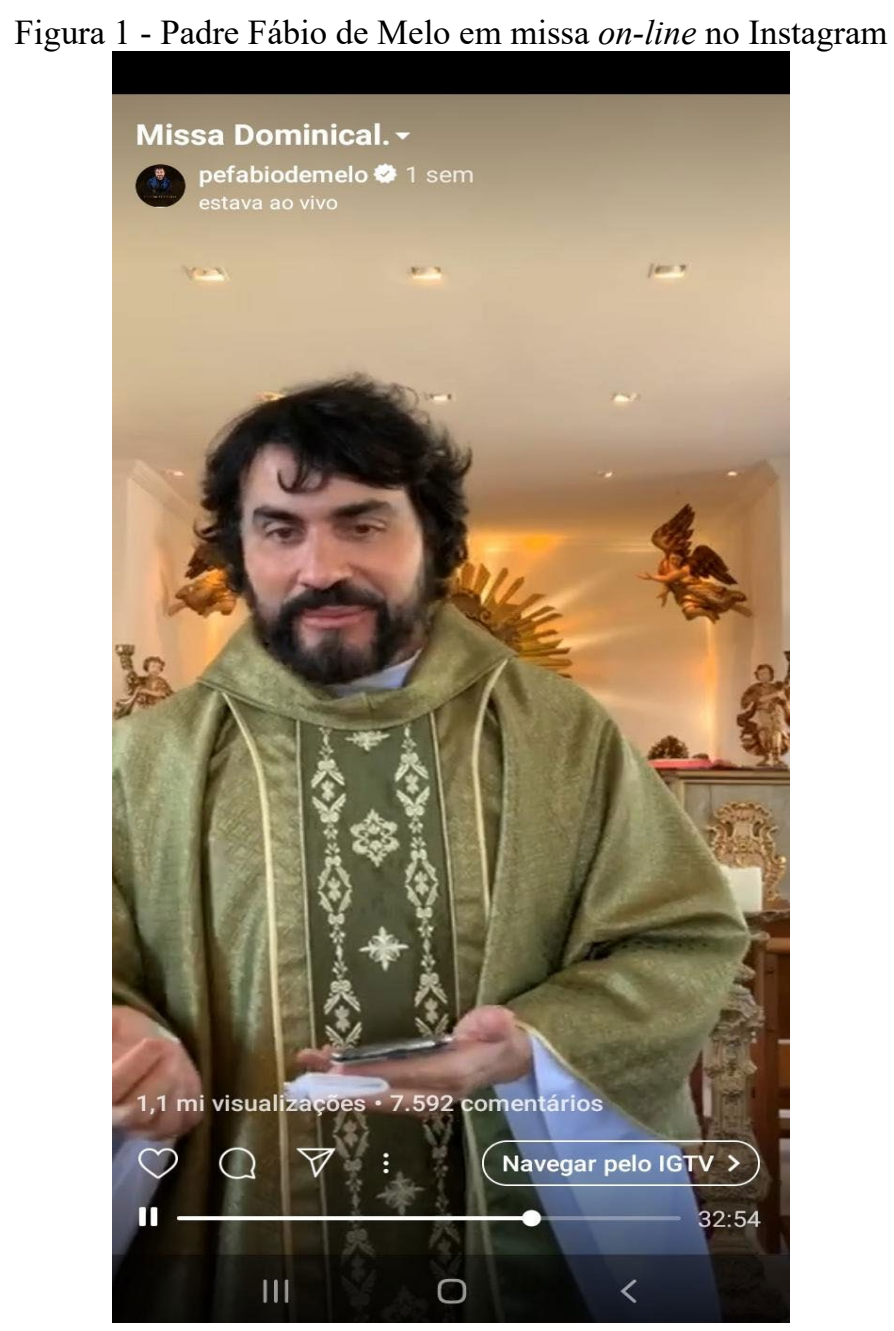


Fonte: Instagram do Pe Fabio de Melo (2020 $)^{17}$

As missas, cultos e mensagens on-line são marcadas por posturas, linguagens gestuais e tonalidades que buscam efeitos de sentidos de proximidade, vínculo e contato (VERÓN, 2013). Além das interações constantes, por meio de distintos dispositivos tecnológicos, há mudanças quanto ao espaço, indumentárias, iluminação, sonorização, entre outras adaptações e reconfigurações. Algumas vezes, como ocorre no exemplo da Figura 1, busca-se reproduzir as práticas religiosas de modo semelhante ao que ocorre nos templos, mas de forma adaptada e ampliada quanto aos recursos, regramentos e possibilidades das plataformas. Evidencia-se, em todo caso, uma constante experimentação, um processo tentativo que acarreta mudanças frequentes no fazer religioso, embora conserve marcas linguísticas, símbolos e referências contextuais próprias às denominações religiosas a que os atores sociais pertencem.

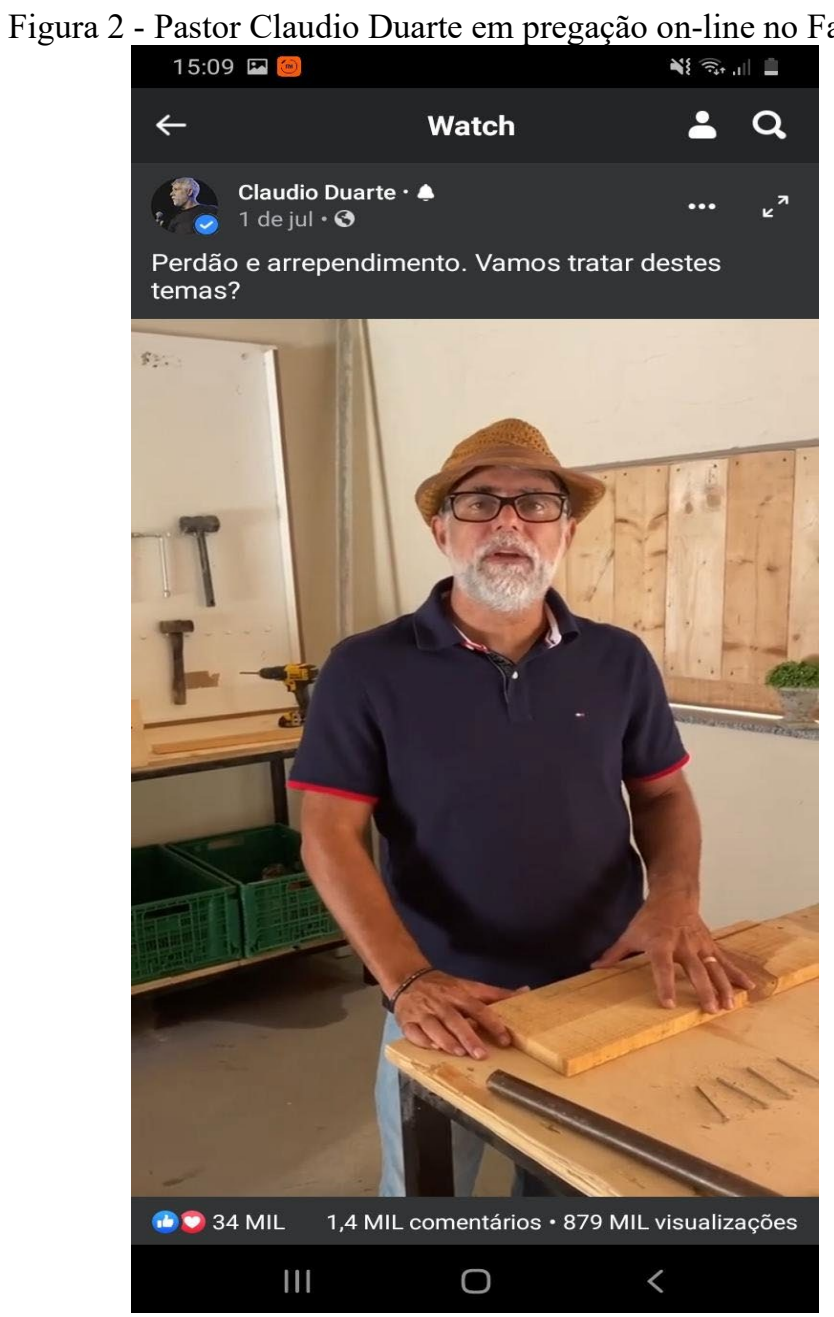

17 Disponível em www.instagram.com/pefabiodemelo. Acesso 15 jul 2020. 


\section{Fonte: Instagram do Pastor Claudio Duarte ${ }^{18}$}

Também ocorre, não apenas devido à necessidade gerada pela pandemia, mas a partir das possibilidades que as plataformas digitais oferecem, a construção de outras formas de contato, através de transmissões ao vivo com interação constante ou de pequenos vídeos em tom de conversa ou em forma de esquetes, nos quais os atores religiosos envolvidos buscam reativar e manter o vínculo com seus seguidores. Algo que se pode ver na Figura 2, em que o pastor transfere sua mensagem a outro ambiente no qual pode lançar mão de recursos alegóricos e ao mesmo tempo interagir com os fiéis. Elementos que já fazem parte da comunicação religiosa, como a linguagem metafórica e a atividade de aconselhamento espiritual são ampliados em seu alcance pelo incremento da atuação em vídeo, dos recursos de edição, da interação e compartilhamentos, entre outros.

Figura 3 - Pastor Claudio Duarte em live no Youtube

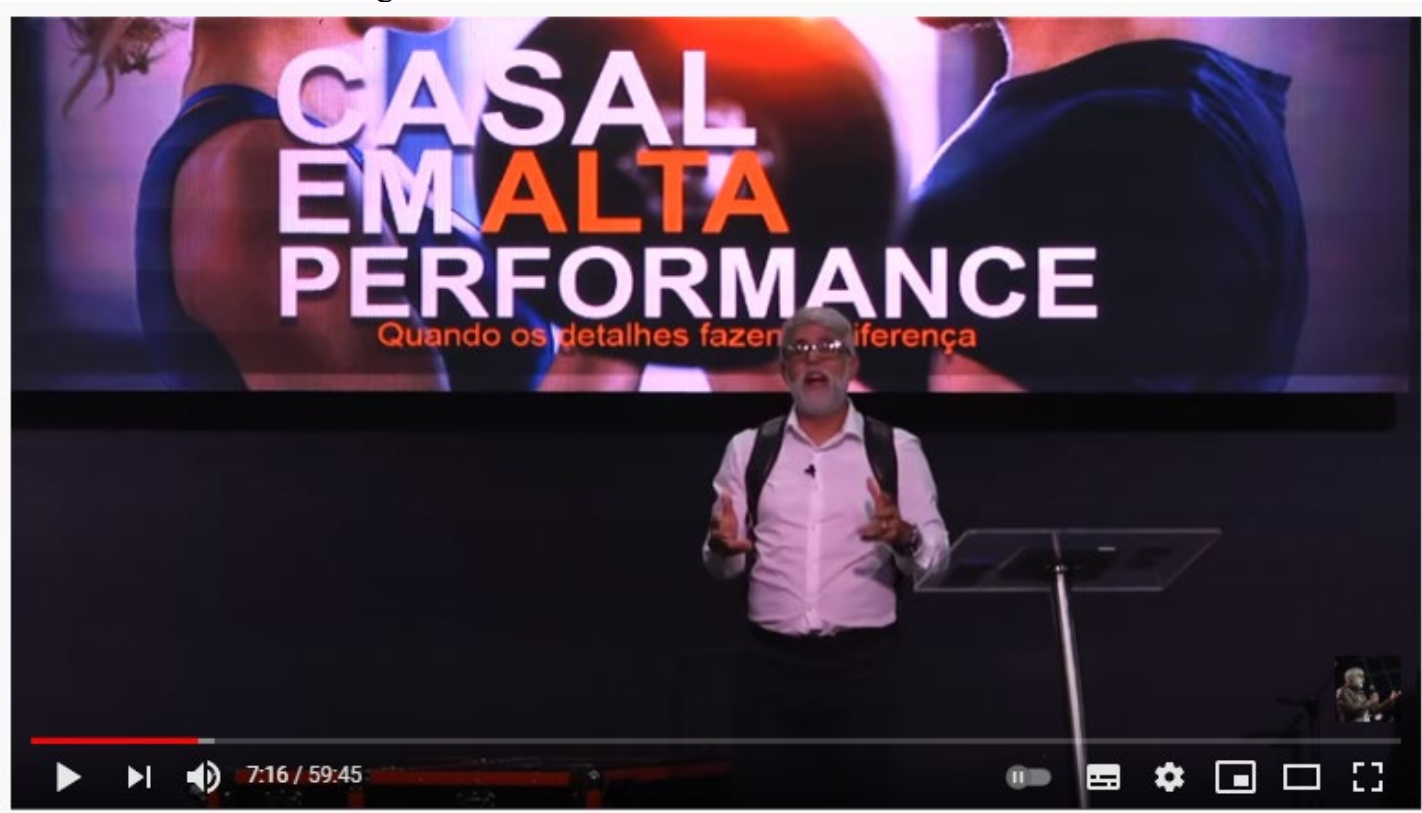

Fonte: Canal do Youtube Pastor Claudio Duarte (2021) ${ }^{19}$

Na Figura 3, mais um exemplo de como essa natureza midiática da religião se associa à midiatização em curso: uma transmissão ao vivo (live) com temática e estilo de produção bastante adaptada do ponto de vista da linguagem, da escolha e organização espacial dos elementos visuais, das posturas que recorrem a lógicas em uso corrente na sociedade. Em sua atuação, o pastor busca manter sempre atualizada a imagem que projeta de si mesmo, assim

\footnotetext{
${ }^{18}$ Disponível em www.facebook.com/ClaudioDuartePastor. Acesso 15 jul 2020.

${ }^{19}$ Disponível em: https://www.youtube.com/watch?v=FRYm112IUNo. Acesso 31 mar 2021.
} 112 
como o tipo de interação que pretende com seus fiéis, ao mesmo tempo em que conserva a sacralidade de sua atividade.

De modo diferenciado, mas ainda em direção semelhante, a Figura 4 traz o exemplo de outra live, agora de um padre via Instagram. Ao mesmo tempo em que apresenta aspectos próprios de sua religião, também trata de temáticas de interesse geral e constrói distintos vínculos com seus fiéis e com outros seguidores ou admiradores, segundo os recursos que a plataforma the possibilita.

Figura 4 - Live do Padre Fábio de Melo com a apresentadora Rafa Brites

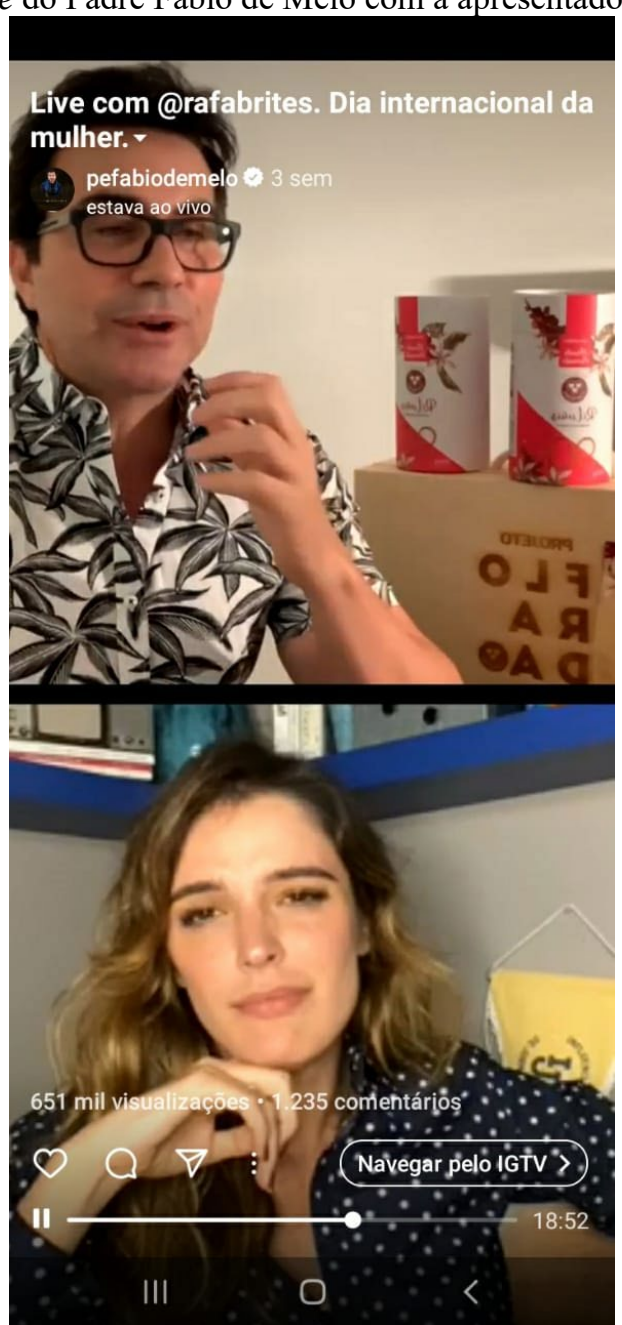

Fonte: Instagram do Pe Fabio de Melo (2021) ${ }^{20}$

Assim, o que ocorre com as religiões em midiatização é não somente a transposição dos conteúdos e ritos para os outros lugares, mas as contínuas adaptações na linguagem e nos discursos produzidos para que gerem determinados efeitos de sentidos por meio de distintos dispositivos midiáticos. Como afirma Borelli (2010), não se trata de uma mera transposição de

${ }^{20}$ Disponível em www.instagram.com/pefabiodemelo. Acesso 08 mar 2021. 
linguagens, técnicas ou uso de dispositivos para permanecer em contato com os fiéis, mas na transformação das religiosidades, visto que os atores sociais envolvidos nessas processualidades passam a vivenciar a experiência religiosa de outro modo.

Esse processo, é claro, não ocorre de modo uniforme, mas de acordo com condições históricas e sociais do próprio campo religioso e seus subcampos. Por isso, para compreender melhor o processo de midiatização da religião, é necessário identificar, em cada caso específico, como essas processualidades se manifestam, especialmente se levarmos em conta a diversidade e complexidade do cenário religioso brasileiro.

Atentando para a complexidade e a diversidade de processualidades que concernem à midiatização da religião, estaremos contribuindo para uma melhor compreensão de como esse processo, que, como vimos, remonta às origens da humanidade, se desenvolve de modo acentuado na atualidade. Ao identificar algumas características dessas relações complexas, os estudos que trabalham na interface mídia e religião podem contribuir para compreensão comunicacional dos fenômenos religiosos.

\section{Considerações finais}

Buscamos, com essas reflexões teóricas e a articulação entre exemplos de nossa pesquisa e estudos que nos antecederam, situar a midiatização da religião como um processo que é integrado ao modo como o ser humano interage com a realidade que o cerca, assim como ao próprio ato de dar sentido às suas convicções e práticas. Apontando para as raízes históricas desse processo em uma escala maior do que a que costumeiramente se destaca (relacionado apenas aos avanços tecnológicos do fim do século XX e início do XXI), consideramos que, assim como se fala em uma natureza midiática da experiência humana, é realmente possível falar em uma natureza midiática da religião.

O que ocorre é que, na atualidade, a midiatização da religião tem assumido outras formas e variadas processualidades, conforme a predominância de outros dispositivos midiáticos, que dão lugar a diversificadas interações de ordem técnica e simbólica. Assim, são observáveis diferentes transformações do fazer religioso, impulsionadas por estratégias comunicacionais elaboradas por indivíduos, coletivos, ou mesmo por instituições e igrejas.

Como afirmam Fausto Neto (2006) e Verón (2013), a tendência é se evidenciarem muito mais complexidades do que uniformidades nas sociedades em vias de midiatização. Como ocorre em outras áreas de conhecimento, cabe ao pesquisador do campo da Comunicação descortinar o que há de peculiar do ponto de vista das variáveis e estratégias envolvidas, bem 
como relacionar, a partir dessas peculiaridades, recorrências e tendências que possam ser tensionadas com as elaborações teóricas já consolidadas e fomentar novas proposições.

Compreender um processo social enquanto ele se desenvolve não é tarefa fácil, pois vive-se num contexto histórico no qual as transformações se dão de maneira cada vez mais acelerada e difusa, ficando difícil demarcar fechamento de ciclos ou períodos para que se possa apreender o que neles se passa. Assim, o estudioso de fenômenos que envolvem a midiatização precisa estar imediatamente atento enquanto esses se desenrolam, tomando-os em sua especificidade e novidade, mas sem perder a dimensão da historicidade que os inscreve em processos epistemológicos e sociais muito mais abrangentes.

Nesse sentido, consideramos que as reflexões aqui levantadas permitem uma compreensão mais alargada do processo no qual se inscrevem os fenômenos religiosos em sua relação com a experiência humana e a comunicação. Além disso, esse olhar histórico sobre a experiência humana, sobre a religião e sobre a midiatização nos ajuda a compreender algumas características que apontam para especificidades, mas também a pontos comuns entre esses campos de conhecimento. As reflexões aqui elencadas abrem caminho para a identificação de outras possíveis abordagens acerca de fenômenos ligados à midiatização da religião, fazendonos olhar para o fenômeno enquanto constitutivo da experiência humana e que remete a relações complexas.

\section{Referências}

ARMSTRONG, Karen. Uma história de Deus: quatro milênios de busca do judaísmo, cristianismo e islamismo. São Paulo: Companhia das Letras, 1994.

BORELLI, Viviane. Mídia e Religião: entre o mundo da fé e do fiel. Rio de Janeiro: E-Papers, 2010.

BRAGA, José Luiz. Mediatização como processo interacional de referência. Animus, Santa Maria, v. 5, n..2, p.9-35, jul/dez. 2006.

BRAGA, José Luiz. Constituição do campo da comunicação. Verso e Reverso, São Leopoldo, v. 25, n. 58, p.62-77, jan/abr. 2011.

FAUSTO NETO, Antonio. Midiatização - prática social, prática de sentido. In: ENCONTRO ANUAL DA COMPÓS, 15. 2006. Anais [...]. Bauru, 2006, p.1-15.

FAUSTO NETO, Antonio. Processos midiáticos e construção das novas religiosidades: dimensões discursivas. Galáxia, São Paulo, v. 2, n. 3, p. 151-164, 2002. 
FAUSTO NETO, Antonio. Mediação, midiatização: conceitos entre trajetórias, biografias e geografias. In: FERREIRA et al. Entre O Que Se Diz E O Que Se Pensa: Onde Está A Midiatização? Santa Maria: FACOS-UFSM, 2018, p.63-99. Disponível em: http://midiaticom.org/files/entreoquesedizeoquesepensa.html?fbclid=IwAR0HnSsKcCY5W3 ntQr1onQILXgChmD90ousniZSMMalCA5k7Kvd-dgnEAqU. Acesso 31 mar 2021.

FLUSSER, Vilém. A filosofia da caixa preta: Ensaios para uma futura filosofia da fotografia. São Paulo: Huitec, 1985.

FRANÇA, Vera. O objeto da comunicação: a comunicação como objeto. In: HOHLFELDT, Antônio; MARTINO, Luiz C.; FRANÇA, Vera Veiga. Teorias da comunicação: conceitos, escolas e tendências. Petrópolis: Vozes, 2001, p.39-70.

HJARVARD, Stig. The mediatization of religion. A theory of the media as agents of religious change. Northern Lights, v. 6 n.1, 9-26, 2008.

HOOVER, Stewart. Religion in the Media Age. London: Routledge, 2006.

MARTINO, Luís Mauro Sá. Midiatização, norte e sul: pontuações e delineamentos do conceito na pesquisa brasileira e anglo-saxônica. In: FERREIRA, Jatiro et al. (orgs.). Entre o que se diz e o que se pensa: onde está a midiatização? Santa Maria: FACOS - UFSM, 2018.

OTTO, Rudolf. O Sagrado: um estudo do elemento não racional na ideia do divino e a sua relação com o racional. São Bernardo do Campo: Imprensa Metodista, 1985.

RODRIGUES, Adriano Duarte. Experiência, modernidade e campo dos media. Portugal: Biblioteca On Line de Ciências da Comunicação 1999.

RODRIGUES, Adriano Duarte. O paradigma comunicacional: história e teorias. Lisboa: Fundação Calouste Gulbenkian, 2011.

RODRIGUES, Adriano Duarte D.; BRAGA, Adriana A. - A Natureza Midiática da Experiência. In: BARRETO, E. et al.. Mídia, Tecnologia e Linguagem Jornalística. João Pessoa, Editora do CCTA, 2014. p. 188-202.

SCOLARI, Carlos A. Las leyes de la interfaz: Diseño, ecología, evolución, tecnologia. Barcelona: Gedisa, 2018.

VAN DIJCK, J; POELL, T.; DE WAAL, M. The Platform Society. Public Values in a Connective World. Nova York: Oxford University Press 2018.

VERÓN, Eliseo. Esquema para el análisis de la mediatización. Revista Diálogos de la Comunicación, n.48. Lima: Felafacs, 1997.

VERÓN, Eliseo. Midiatização, novos regimes de significação, novas práticas analíticas? In: FERREIRA, Giovandro Marcus; SAMPAIO, Adriano de Oliveira (orgs.). Mídia, discurso e sentido. Salvador: EDUFBA, 2012, p. 17-25.

VERÓN, Eliseo. Ciudad Autónoma de Buenos Aires: Paidós, 2013. 
VERÓN, Eliseo. Teoria da midiatização: uma perspectiva semioantropológica e algumas de suas consequências. Matrizes, São Paulo, v. 8, n. 1, p. 13-19, jan/jun. 2014.

WHITE, Robert. Religion and media in the construction of cultures. In: HOOVER, Stewart M.; LUNDBY, Knut. Rethinking media, religion, and culture. Tradução do PPGCOM Unisinos. Thousands Oaks/ Londres/Nova Deli: Sage Publications. International Educational and Professional Publisher, 1997, p. 37-64.

\footnotetext{
${ }^{a}$ Professora do Programa de Pós-Graduação em Comunicação da UFSM. Doutora em Ciências da Comunicação pela Unisinos.

${ }^{\mathrm{b}}$ Doutorando do Programa de Pós-Graduação em Comunicação da Universidade Federal de Santa Maria (UFSM)
} 